\title{
Encontrando mi enfermedad. Producción de las RELACIONES SOCIALES EN EL GRUPO DE AUTOAYUDA Nuevo ATARDECER DE CUARTO Y QUINTO PASO
}

\author{
Finding my Illness. Production of Social \\ Relationships in the New Sunset Self-help Group \\ of Fourth AND FifTh STEP
}

\author{
Damián Cruz González* \\ DOI: https://doi.org/10.31644/ED.V8.N1.2021.A09
}

\begin{abstract}
Resumen: El objetivo de este artículo es comprender el proceso de producción del mundo social que construyen las y los participantes del grupo Nuevo Atardecer de San Cristóbal de Las Casas, Chiapas. A partir de la antropología del poder, se construyó una radiografía etnográfica para conocer más a fondo cómo operan este tipo de grupos de ayuda mutua y cómo la historia muestra una dinámica de rupturas en la formación de los mismos. Se pretende mostrar los múltiples conflictos, tensiones y negociaciones que se desarrollan al interior de este, para dar a conocer un espacio social que no es sistemático ni cuenta tampoco con una visión o unos intereses comunes. Además, se propone visibilizar diversos fenómenos que se construyen durante el proceso de producción, por ejemplo, la invención de una enfermedad.
\end{abstract}

Palabras clave: antropología del poder, organización, ayuda mutua, autoayuda, lenguajes, Chiapas

Abstract: The objective of this article is to understand the production process of the social world undergone by members of the New Sunset group in San Cristobal de Las Casas, Chiapas. Drawing from anthropology of power, an ethnographic radiography was drawn to learn more about how these types of mutual aid groups operate and how history shows a dynamic of ruptures in their formation. An attempt will be made to show the multiple conflicts, tensions and negotiations that take place within it to account for a social space that is not systematic, nor does it have a common vision or interests. In addition, it is intended to make visible various phenomena that are constructed during the production process, for example, the invention of a disease.

Keywords: anthropology of power, organization, mutual aid, self-help, idioms, Chiapas. * Investigador independiente, Mtro. en Antropología Social, Centro de Investigaciones y Estudios Superiores en
Antropología Social, Unidad Sureste, México. Correo-e: $\underline{\text { damianroller@hotmail.com. }}$

Fecha de recepción: 26/06/2020. Fecha de aceptación: 03/11/2020. Fecha de publicación: 30/01/2021.

(cc) BY-NC-ND

EntreDiversidades. Revista de Ciencias Sociales y Humanidades, vol. 8, núm. 1 (16), enero-junio 2021. Páginas: 212 - 240 ISSN-e: 2007-7610. https://doi.org/10.31644/ED.V8.N1.2021.A09 


\section{Introducción}

El artículo presentado es una síntesis de la tesis de la maestría "Encontrando mi enfermedad. Producción de las relaciones sociales en el grupo Nuevo Atardecer de cuarto y quinto paso" (Cruz, 2018). En concreto, se ocupa de atender varias interrogantes que salieron a relucir durante el trabajo de campo: ¡cómo se produjo y se sigue reproduciendo el espacio social del grupo Nuevo Atardecer de cuarto y quinto paso? y ¿qué otros tipos de fenómenos sociales durante el proceso de producción se construyen? Estas preguntas me sirvieron para encaminar mi trabajo de investigación, no hacia un resultado, sino hacia la construcción de una radiografía etnográfica, a partir de una "etnografía del poder" (Escalona, 2012), para comprender el proceso de este complicado mundo social que construyen los integrantes del grupo Nuevo Atardecer de San Cristóbal de Las Casas, Chiapas. Me refiero a una organización que es denominada "grupo de cuarto y quinto paso", cuyo propósito principal es la recuperación de las personas que presentan abusos de alcohol, drogas y tienen conflictos con sus emociones. Mi interés radica entonces en comprender las dinámicas sociales que se desarrollan al interior de esta organización para visibilizar las estrategias que utilizan para reproducir y transformar las relaciones sociales y su espacio social. Además, el estudio intenta mostrar los múltiples conflictos, tensiones y negociaciones que se desarrollan entre los integrantes y al interior de este grupo, para dar cuenta de un espacio social que no es lineal, ni sistemático, ni cuenta tampoco con una visión o unos intereses comunes.

Por otro lado, mi inclusión en el grupo Nuevo Atardecer fue mediada a través de un miembro de la organización. Esta persona me propuso su grupo como objeto de estudio. Así pues, me indicó que este sesionaba seis días a la semana por la noche. Es amigo del fundador de la organización y tiene muchos años asistiendo a los grupos de cuarto y quinto paso. Cuando me presenté en la organización, resolví decir que era alcohólico, debido a que todavía no sentía confianza suficiente para contarles sobre la investigación; después, más que ser visto como estudiante de antropología, fui considerado como padrino.

Durante mi trabajo de campo, mi percepción cambiaba constantemente con respecto al grupo Nuevo Atardecer. Al principio me concentré en describir, desde una visión terapéutica y social, la mayoría de los efectos negativos producidos por las actividades "rituales" en las y los participantes, así como los procesos de transformación que se daban entre los mismos, por lo que mis propósitos estaban relacionados con objetivos sociales y de salud pública. De igual forma, durante mi estancia en la organización pasé muchos días en los que me sentía aburrido; pensaba que ya había descrito y observado todo, no encontraba motivación para seguir, así que consideré cambiar de local para explorar nuevas dinámicas. Llegué a creer, por lo tanto, que mi trabajo en este primer espacio podía darse por concluido.

Asimismo, constantemente me cuestionaba sobre mi intervención como observador y participante, ya que dudaba de si realmente me habría perdido en la descripción y procesos de los ejercicios - por tratar de interpretar el sentido que los integrantes les dan a las actividadesy tal vez había dejado de lado la comprensión de otros aspectos de la vida social del grupo. Por ello, a veces me preguntaba: “¿qué se me estará pasando...? ¿Habrá aquí algo más que

EntreDiversidades. Revista de Ciencias Sociales y Humanidades, vol. 8, núm. 1 (16), enero-junio 2021. Páginas: 212 - 240 ISSN-e: 2007-7610. https://doi.org/10.31644/ED.V8.N1.2021.A09 
examinar...?”. Entonces, antes de tomar la decisión de cambiar de grupo, decidí hablar con algunos investigadores, quienes me propusieron que tratase de seguir asistiendo por un tiempo más, a lo que finalmente accedí.

Después de varias sesiones mi perspectiva (en cuanto a los planteamientos que me había puesto antes de salir de campo) comenzó a modificarse; recordé haber leído algunas etnografías antes y al final del trabajo de campo, específicamente una sobre el poder (Escalona, 2012). De repente, me di cuenta de que no consideré algo: las tensiones en las relaciones sociales del grupo. No las había querido atender porque pensaba que el poder, los conflictos y contradicciones se observan y se dan de la misma forma en todas partes. Todo el tiempo estuvieron ahí; sin embargo, reflexioné y me di cuenta de que lo había normalizado y naturalizado. Además, creía que no eran tan importantes como los rituales de transformación y el sentido que los miembros les dan a estos.

De esta manera, percibí una serie de mensajes que eran reiterativos, intencionados y retóricos. Me encontré, en un primer momento, dentro de este caos y empecé a dilucidar cosas; una de ellas es que hay una serie de lenguajes particulares. En medio de este desorden identifiqué diversos discursos que dominan, producen diversos significados, sentidos y contradicciones. Esto me llevó a plantearme el poder de los lenguajes.

El trabajo de estudio se fundamenta en observación participante en el grupo denominado Nuevo Atardecer de cuarto y quinto paso de San Cristóbal de Las Casas, Chiapas. La investigación se realizó del 1 de septiembre del 2017 al 15 de diciembre del mismo año. Realicé 11 entrevistas ${ }^{1}$ audio-grabadas que posteriormente transcribí y más de 72 charlas informales con los miembros del grupo, tanto dentro como fuera de la organización. Durante algunas entrevistas mi posición como estudiante de antropología fue desplazada por la de "padrino", y esta última tuvo mayor presencia que la otra. Sin embargo, la voz de este papel no tuvo tanto eco en la vida de la gente que entrevisté. También asistí como apoyo a tres retiros que realizó el grupo.

\section{Enfoques sobre los grupos de autoayuda}

La proliferación de los grupos de "autoayuda" o "ayuda-mutua" en México no ha pasado desapercibida en la investigación. Diversos investigadores e investigadoras que han estudiado estos grupos — que son muy diversos, por ejemplo, hay grupos para los que beben, abusan de las drogas, dependen emocionalmente de otras personas, entre muchos otros- señalan que su origen se debe a "la compleja situación política, religiosa y de múltiples desigualdades sociales" (Córdova, 2018: 58), también a "una alternativa de ayuda mutua a AA [Alcohólicos Anónimos]" (White, 2015: 2) o a la falta de atención por parte del Estado (Odgers y Olivas, 2018). Otros, mencionan que todas estas organizaciones "dan lugar a la construcción de redes sociales, interacciones e identidades, aun en sociedades con distintas características" (Rosovsky, 2009: 14).

Asimismo, las formas de operación de estos grupos, sus significados, los elementos religiosos (Gutiérrez, 2014, Odgers y Olivas, 2018) o espirituales (Córdova, 2018, Anderson y Garcia, 2015, White, 2015, Garcia, Anderson y Humphreys, 2015) —que terminan por "transformar" al adepto en un ser diferente o, más bien, liberarlo de la dependencia del alcohol,

\footnotetext{
${ }^{1}$ Ver cuadro anexo.
}

EntreDiversidades. Revista de Ciencias Sociales y Humanidades, vol. 8, núm. 1 (16), enero-junio 2021. Páginas: 212 - 240 ISSN-e: 2007-7610. https://doi.org/10.31644/ED.V8.N1.2021.A09 
las drogas o conflictos emocionales_-, o hasta la misma denominación "grupos de ayuda mutua" (Menéndez, 1991, Martín, et al., 2000), son investigados o asumidos como partes específicas de un "modelo terapéutico"2. De este modo, estas organizaciones son definidas por varios investigadores e investigadoras como "grupos creados, desarrollados, utilizados, mantenidos por sus propios miembros; más aún, son los propios miembros del grupo los que se encargan del 'tratamiento"” (Menéndez, 2009: 112). Además, los métodos utilizados en estas agrupaciones solamente son observados como catalizadores de "efectos positivos en la salud psicológica de diversos individuos" (Di Pardo, 2009: 173). En este aspecto, al parecer existe la idea de que hay una especie de transformación de los integrantes, parecida a la que se tiene sobre algunos tipos de terapia o rituales. Pero lo que en realidad existen son tensiones, conflictos y diferencias que se desdoblan incluso como estrategias de la "ayuda mutua" (muy alejado de las ideas que se tienen sobre las reuniones donde las personas cuentan sus experiencias en un lenguaje amable y reciben consuelo).

De esta manera, cuando se presentan conflictos, tensiones y distinciones entre los miembros de estas organizaciones estos elementos son abordados por varios analistas como obstáculos "en la realización de algunos principios fundamentales de la institución, así como en las prácticas de la ayuda mutua” (Módena, 2009: 31), más que como estrategias o formas de interacción que han sido producidas/reproducidas, consciente o inconscientemente, por los mismos integrantes y se despliegan por todo el espacio social. Estos espacios sociales son más complejos de lo que se piensa, como lo deja ver Córdoba en su estudio sobre la construcción social del sujeto adicto (2018).

Podemos decir, entonces, con respecto a nuestra mirada de estudio, que cada organización social de los grupos de cuarto y quinto paso está traspasada por "una serie —económica, política, militar, comercial, religiosa - de dinámicas sociales" (Escalona, 2014: 178); es decir, el grupo de cuarto y quinto paso es una manifestación del entrecruzamiento e interacciones de múltiples dinámicas sociales, por lo tanto es un espacio transpuesto, mediado "por jerarquías, competencia y asociación estratégica —en síntesis, por dinámicas de poder-” (Escalona, 2014: 184). Así, más que representar una "institución", "grupo de ayuda mutua" o "autoayuda", hablaremos de una organización social producida y que se sigue reproduciendo por diferentes dinámicas de rupturas, lenguajes y prácticas.

En este sentido, la mayoría de los trabajos de investigación sobre los grupos de cuarto y quinto paso que se han realizado hasta la fecha (Vega, 2009, Garcia, Anderson y Humphreys, 2015, White, 2015, Anderson y Garcia, 2015, González, 2015; y otro que está en proceso de terminarse: Chávez, 201833) se centran precisamente en el método de "recuperación" que utilizan estas organizaciones, y cómo este repercute en las subjetividades y emociones de las personas, es decir, como un método "transformador" de las mismas. Si bien las investigaciones se realizaron en grupos diferentes, estas dejaron de lado un aspecto que me interesa abordar en este estudio: ¿cómo se produce un grupo de cuarto y quinto paso?, así como ¿qué otros fenómenos sociales se producen en este espacio para su operación?

\footnotetext{
${ }^{2}$ Este modelo terapéutico conlleva diversas ideas, características, categorías y demás sobre el mundo social de los grupos de autoayuda, por ejemplo: farmacodependientes, oferta de atención a las adicciones, componentes religiosos o espirituales, ideologías de AA (Alcohólicos Anónimos), etcétera.

${ }^{3}$ La experiencia espiritual. Atención a consumidores problemáticos de drogas en grupos de $4^{\circ}$ y $5^{\circ}$ paso de la Ciudad de México (Tania Pamela Chávez Águila, en proceso de concluir).
}

EntreDiversidades. Revista de Ciencias Sociales y Humanidades, vol. 8, núm. 1 (16), enero-junio 2021. Páginas: 212 - 240 ISSN-e: 2007-7610. https://doi.org/10.31644/ED.V8.N1.2021.A09 
Aunque el carácter de las emociones y subjetividades es un aspecto que resalta en estas organizaciones, debo precisar que el propósito de este estudio no es enfocarnos en las emociones, ni saber si hay o no una transformación en las y los participantes, ni mucho menos ver cómo tratar de mejorar la terapia, hacer que el proceso sea más eficiente o lograr mejores resultados; pero incluiré varias reflexiones personales de la experiencia vivida en campo. Porque al parecer, parafraseando a Goffman, el secreto que en verdad se oculta detrás del enigma es que en realidad no hay ningún misterio (2012), sino más bien relaciones de poder en constante tensión y conflicto, entre las y los participantes y otras organizaciones, que contribuyeron a la construcción de una práctica curativa para el consumo excesivo de alcohol, drogas o problemas emocionales que los mismos miembros del grupo de estudio llaman "experiencia espiritual". Por tanto, mi interés es penetrar en el mundo social del grupo Nuevo Atardecer de cuarto y quinto paso para proporcionar una comprensión reflexiva de las relaciones sociales y la "experiencia espiritual".

\section{Propuesta teórico-metodológica}

Para realizar esta investigación me apoyé, principalmente, en la propuesta metodológica denominada "etnografía del poder" proporcionada por Escalona (2012). Este autor busca abrir un espacio para proveer un lenguaje que dé cuenta de las formas en las que el poder opera, apoyándose en la teoría de Wolf (2001), en las relaciones hombre-hombre. Esto es, acercarse "a ese proceso de producción simbólica, a las formas de categorización y a las implicaciones de esta producción en la configuración de las relaciones de poder" (Escalona, 2009b: 22). De esta manera, el autor se dirige a "las posibilidades del uso de la noción de poder en el análisis de diversas dimensiones y espacios del mundo social” (Escalona, 2009a: 18), un mundo que no se limita a un ámbito particular de las relaciones. Escalona muestra el poder como un fenómeno transversal que está presente en las relaciones sociales y no solamente constituye un campo específico de estas. Entonces, el poder sería un componente de las relaciones en diferentes dimensiones: políticas, sociales, económicas, religiosas y corporales. Asimismo, el autor indica que el análisis del poder también se encuentra en redes e instituciones translocales. Por tanto, entenderé el poder como una fuerza que atraviesa y opera en las relaciones sociales, el cual es capaz de producir un mundo social de relaciones muy particulares.

La propuesta de la etnografía del poder está armada por cuatro elementos intrínsecos: la condición translocal, contradicciones básicas y arenas de disputa, lenguajes de poder y la producción simbólica. El primer elemento intrínseco de la etnografía del poder, la condición translocal, analiza los procesos organizativos e institucionales, los contactos fluidos con redes e interacciones para señalar que la localidad es el resultado de todos estos entrecruzamientos y reinterpretaciones. Este elemento me ayudó a observar el espacio social del grupo Nuevo Atardecer como producto de las relaciones sociales e interacciones de diversas organizaciones, esto para dar cuenta de cómo ocurre el proceso de construcción social.

La segunda dimensión de la etnografía del poder trata sobre las contradicciones básicas y arenas de disputa. Esta dimensión analiza las manifestaciones de las organizaciones específicas, así como las tensiones y los conflictos en diversos niveles de la vida social. La etnografía del poder se

EntreDiversidades. Revista de Ciencias Sociales y Humanidades, vol. 8, núm. 1 (16), enero-junio 2021. Páginas: 212 - 240 ISSN-e: 2007-7610. https://doi.org/10.31644/ED.V8.N1.2021.A09 
centra en la contradicción y enfoca la vida social como fruto de luchas en torno a bienes valorados en la cotidianidad. Este aspecto me permitió mostrar al grupo como un espacio desorganizado, cambiante, en conflicto y tensión entre las y los participantes.

En tercer lugar, los lenguajes de poder. Este elemento es central en la etnografía del poder, ya que por medio de este se comprenden las relaciones sociales y se analiza la producción simbólica. Los lenguajes de poder son producidos por las diversas formas de representar al mundo, paralelamente están traslapados con otros tipos de lenguajes que explican, de distintas maneras, las vivencias de la vida cotidiana y producen diversos y contradictorios significados; estos originan una mezcla de puntos de vista y elementos argumentativos de la vida cotidiana (Escalona, 2012). Este elemento hizo posible que explicara y analizara una diversidad de lenguajes que percibí en el grupo Nuevo Atardecer de cuarto y quinto paso. De esta forma, comprendí una serie de lenguajes que hablan sobre una "enfermedad emocional" y "física", y se sobreponen con unos lenguajes médicos, religiosos y psicológicos popularizados, los cuales llegan a reproducir un mundo social muy particular, con sus significados, prácticas, posiciones y categorías (Bourdieu, 2006). Asimismo, me ayudaron a comprender las relaciones sociales de poder (diferentes) que se encuentran en tensión (enfrentamientos) y cambio constante.

A partir de estos lenguajes los integrantes clasifican, agrupan y desagrupan diversas cuestiones de la vida cotidiana y les dan un cierto sentido. Además, manipulan en distintas formas los significados, entendimientos, signos y argumentaciones. Aunque sé que no todo se explica por medio del lenguaje, considero que refleja muchas cuestiones que son asumidas como ordenadas. En este ensayo, tomo al lenguaje como un objeto que es producido por los integrantes del grupo, distinguiéndolo del habla individual (Saussure, 1998), que se encuentra insertado en las acciones de los miembros, en sus cuerpos (mímico y gestual) y les sirve como una forma de negociación ${ }^{4}$.

Por último, la producción simbólica propone que la producción de sentidos actual es resultado de diversas formas de manipulación de significados y signos, los usados con anticipación y los recientes, así como las gestaciones de varias interpretaciones y reinterpretaciones (en ocasiones fortuitas). Finalmente, con esta dimensión me propuse analizar el principal método que utiliza esta organización, la llamada "experiencia espiritual", para dar cuenta de las diversas formas en que son producidos y reproducidos los entendimientos y significados de la enfermedad, así como las diversas prácticas de curación.

\section{Los grupos de cuarto y quinto paso}

En el libro Las instituciones voraces, Lewis Coser (1974) señala que en el "mundo moderno" las personas se encuentran encerradas en redes de adhesión de grupos, que constantemente y en distintas maneras reclaman su asociación; estos grupos utilizan diversos mecanismos de motivación para asegurar la fidelidad y lealtad de sus integrantes, debido a que hay una gran cantidad de grupos e instituciones que también compiten por la adhesión de las personas — por ejemplo, colectividades voraces que intentan abarcar toda la personalidad de la gente dentro

\footnotetext{
${ }^{4}$ Estas reflexiones me fueron compartidas por el Dr. José Luis Escalona Victoria.
}

EntreDiversidades. Revista de Ciencias Sociales y Humanidades, vol. 8, núm. 1 (16), enero-junio 2021. Páginas: 212 - 240 ISSN-e: 2007-7610. https://doi.org/10.31644/ED.V8.N1.2021.A09 
de su círculo y ponen sus energías humanas a los fines de sus servicios- En México existen diversas organizaciones sociales que demandan la afiliación de las personas, en particular, hay unas que son distinguidas como grupos de "ayuda mutua" o "autoayuda"; algunos grupos que se consideran dentro de esta denominación se centran en las personas que abusan del alcohol, de las drogas o tienen conflictos emocionales (celos, envidia, ira, entre otros).

La organización a la que me referiré en este artículo es denominada grupos de cuarto y quinto paso, la cual se enfoca en recuperar a mujeres y hombres que exceden el consumo del alcohol, de las drogas o tienen conflictos emocionales. El primer grupo surgió en la Ciudad de México en 1991, a partir del conflicto que hubo entre miembros de un grupo de Alcohólicos Anónimos (AA). Con el paso del tiempo, los grupos de cuarto y quinto paso se han expandido hacia varios estados de México, incluso se hallan en otros países como Chile, Perú, Guatemala, Estados Unidos de América ${ }^{5}$ y España ${ }^{6}$. Se pueden encontrar una gran diversidad de grupos, ya que cualquier persona que ha participado en alguna organización parecida (AA, los llamados "anexos" y otros grupos de cuarto y quinto paso) puede conformar uno.

En lo concerniente al nombre de esta organización, varios de los iniciadores decidieron utilizar como referente el título de dos de los 12 pasos $^{7}$ de AA: “4. Sin miedo hicimos un minucioso inventario moral de nosotros mismos y 5 . Admitimos ante Dios, ante nosotros mismos, y ante otro ser humano, la naturaleza exacta de nuestros defectos". Con esto, los integrantes quisieron concentrarse en curar a las personas que abusan del alcohol, las drogas o

\footnotetext{
${ }^{5}$ Por información localizada en redes sociales, se sabe que estos grupos se han expandido por la mayoría de las entidades federativas de México, también se han encontrado en países como Estados Unidos de América (Garcia, Anderson y Humphreys, 2015), Guatemala, Perú y Chile https://www.facebook.com/gruposdecuartoyquintopaso/ posts/840013402727693 (Grupos de Cuarto y Quinto Paso de Amor y Servicio, 2012) https://www.youtube.com/ watch?v=gaKQHjL9Uis (Bosco, 2017).

${ }^{6}$ Una persona de España me comentó que hay varios grupos de cuarto y quinto paso en Oviedo, Asturias, España.

${ }^{7}$ Los 12 pasos de recuperación del programa de Alcohólicos Anónimos, y que algunos grupos de ayuda mutua adaptan a sus necesidades específicas, están conformados así:

1. Admitimos que éramos impotentes ante el alcohol, que nuestras vidas se habían vuelto ingobernables.

2. Llegamos a creer que un poder superior podría devolvernos el sano juicio.

3. Decidimos poner nuestras voluntades y nuestras vidas al cuidado de Dios, como nosotros lo concebimos.

4. Sin miedo hicimos un minucioso inventario moral de nosotros mismos.

5. Admitimos ante Dios, ante nosotros mismos, y ante otro ser humano, la naturaleza exacta de nuestros defectos.

6. Estuvimos enteramente dispuestos a dejar que Dios nos liberase de todos estos defectos de carácter.

7. Humildemente le pedimos que nos liberase de nuestros defectos.

8. Hicimos una lista de todas aquellas personas a quiénes habíamos ofendido y estuvimos dispuestos a reparar el daño que les causamos.

9. Reparamos directamente a cuantos nos fue posible el daño causado, excepto cuando el hacerlo implicaba perjuicio para ellos o para otros.

10. Continuamos haciendo nuestro inventario personal y cuando nos equivocábamos lo admitíamos inmediatamente. 11. Buscamos a través de la oración y la meditación mejorar nuestro contacto consiente con Dios, como nosotros lo concebimos, pidiéndole solamente que nos dejase conocer su voluntad para con nosotros y nos diese la fortaleza para cumplirla.

12. Habiendo obtenido un despertar espiritual como resultado de estos pasos, tratamos de llevar este mensaje a los alcohólicos y de practicar estos principios en todos nuestros asuntos (A. A. Grapevine, 1993).
}

EntreDiversidades. Revista de Ciencias Sociales y Humanidades, vol. 8, núm. 1 (16), enero-junio 2021. Páginas: 212 - 240 ISSN-e: 2007-7610. https://doi.org/10.31644/ED.V8.N1.2021.A09 
tienen conflictos emocionales. Asimismo, para conseguir la "liberación” o "recuperación” de las personas, produjeron un método que es denominado por los miembros como la "experiencia espiritual" (también llamados retiros espirituales).

Los retiros espirituales consisten en una serie de prácticas, pero principalmente en hacer un inventario moral $^{8}$ de la persona, mediante un cuestionario compuesto de varias preguntas ${ }^{9}$ que se les dicta a las y los participantes. A las personas que van a escribir la "experiencia espiritual" se les denomina escribientes. Algunos integrantes piensan que si el escribiente contesta todas las preguntas "honestamente" desenredará su pasado, ya que esta práctica le ayudará a analizar varias situaciones y pensamientos que le causaron aversión y repugnancia, entonces, al finalizar el retiro obtendrá una "liberación" emocional y física (Castro, 2000: 3).

Varias de las personas que participan en estos retiros por distintas razones, más argumentativas que de otro tipo, y voluntad propia, tienen el convencimiento de que este acto las va a "transformar". Estas ideas de conversión tienen mucho que ver con la opinión de la familia, los amigos y gente cercana, ya que no siempre los miembros están de acuerdo con el acto del "retiro espiritual". En este espacio los integrantes intentan buscar soluciones a sus problemas, aunque no siempre las encuentran. Lo que quiero resaltar de este tipo de grupos es el proceso por el cual se produce un grupo de cuarto y quinto paso y la excesiva manipulación de los entendimientos del mundo social y significados del lenguaje, que hacen posible que se produzcan otro tipo de fenómenos sociales, como la invención de una enfermedad: "gracias a Dios ahora que viví la 'experiencia espiritual' ya me doy cuenta que mi familia está enferma emocionalmente” (Entrevista con Julieta, 2017); en este espacio, los integrantes intentan mostrarles a las y los recién llegados que siempre hay una enfermedad detrás de los conflictos personales. Así pues, nuestro propósito principal es mostrar cómo se tejen las relaciones de poder en la dinámica de las relaciones sociales del grupo Nuevo Atardecer de cuarto y quinto paso.

\section{La producción del grupo Nuevo Atardecer}

En el municipio de San Cristóbal de Las Casas se han constituido diversas organizaciones: alrededor de 55 grupos $^{10}$ de Alcohólicos Anónimos; también los llamados "24 horas", que son un tipo de centro de rehabilitación para personas que tienen problemas con el alcohol y

\footnotetext{
${ }^{8}$ Escribir todas las situaciones trágicas, desagradables, repugnantes, dolorosas y vergonzosas que haya pasado la persona.

9 "Mirando el pasado ¿̨Puedo darme cuenta cómo, cuándo y dónde se descoyuntó mi instinto sexual y qué fue lo que sentí: miedo, ansiedad o frustración? ¿Actualmente qué tipo de situaciones sexuales me causan miedo, ansiedad o frustración? ¿Actualmente qué tipo de situaciones me causaron miedo, ansiedad o frustración en el aspecto material y emocional? ¿En el aspecto social qué tipo de situaciones me causaron miedo, ansiedad o frustración? ¿Resentimientos? ¿Actualmente qué tipo de situaciones me causan asco y repugnancia de mí mismo?”. Estas preguntas fueron recogidas en el trabajo de campo, ya que dependiendo del grupo las preguntas pueden variar.

${ }^{10}$ Para más información se puede consultar la página de internet: https://www.aamexico.org/directorio grupos estado.php?lista municipios $=158 \&$ colonia municipio $=$
}

EntreDiversidades. Revista de Ciencias Sociales y Humanidades, vol. 8, núm. 1 (16), enero-junio 2021. Páginas: 212 - 240 ISSN-e: 2007-7610. https://doi.org/10.31644/ED.V8.N1.2021.A09 
las drogas; varias organizaciones nombradas como "anexos"11; los denominados "new age" 12 y algunos grupos de cuarto y quinto paso.

En el caso que me atańe, el grupo Nuevo Atardecer de cuarto y quinto paso fue conformado a iniciativa de una persona llamada Roberto. Él fue llevado por su cuñado a un grupo de estos, denominado Revolución; esta organización realizaba "experiencias espirituales" una vez al mes. Roberto, tras ser engañado por su cuñado, fue al retiro espiritual, y al terminar la "experiencia" se dio cuenta de que bebía alcohol y consumía drogas compulsivamente porque padecía de una enfermedad emocional y física.

Con el paso del tiempo, Roberto se separó de dicho grupo porque no le agradaron las actitudes del encargado: este le robó el dinero a un integrante, por ejemplo. Además, a Roberto se le hacía el grupo "una asquerosidad y sus juntas muy desagradables" (Entrevista con Roberto, 2017). Todos estos acontecimientos, entre otros, hicieron que Roberto en una junta del grupo Revolución confrontara al encargado y decidiese salirse junto con otros miembros. Por lo que él comentó, después de enfrentar al encargado adquirió simpatía por parte de algunos integrantes, lo que conllevó a que estos lo siguieran y lo animaran a conformar un grupo de cuarto y quinto paso. A partir de aquí Roberto es distinguido como el principal precursor del grupo.

Después de la ruptura, un integrante le seńaló a Roberto que todo lo que había pasado en la agrupación no le debía de importar, ya que "va al grupo a 'recuperarse', no a enfermarse"13 (Entrevista con Luis, 2017). Este fragmento expone una de tantas estrategias que utilizan varios de los y las participantes para encubrir las fallas de la organización o intentar persuadir a los miembros a no dejar el grupo. Asimismo, se puede observar que en esta organización social no existe una visión común o ideología, porque los intereses de varios integrantes del grupo Revolución eran muy diferentes al de los demás, y continuamente cambiaban por querellas o por la llegada de otras personas.

Esta situación muestra cómo las diferencias de poder, los intereses desiguales, los conflictos y tensiones entre las y los participantes, en los que se encuentran implícitas diversas circunstancias, hicieron que se produjera otro espacio social particular. Las "prácticas organizativas tienen muchas veces un carácter fragmentado, no colectivo" (Appendini y Nuijten, 2002: 257), y es necesario visibilizar y explicar las dinámicas sociales "para comprender las formas en que el mundo social se construye y transforma a través de la acción cotidiana"14 (Escalona, 2016: 250).

Además de producirse un espacio social particular, también se reprodujo un cierto tipo de "conocimiento", con múltiples interpretaciones, defectos y manipulaciones, en cuanto a la construcción de grupos. Cuando los miembros decidieron conformar el grupo vieron que era necesario acudir no a un manual sino a gente que, para ellos, ya tuviera experiencia y conocimiento

\footnotetext{
${ }^{11}$ Estos son centros de rehabilitación para personas que abusan del alcohol y drogas, se manejan con un lenguaje violento, en ocasiones hay maltrato físico.

${ }^{12}$ Este movimiento ha sido vinculado con las costumbres indígenas locales tsotsiles, $\mathrm{y}$ articulado con otras tradiciones espirituales como la budista o la chamánica. Algunas características son creencias en extraterrestres, el cuidado del cuerpo, la opción por la medicina alternativa, entre otras (Pinto y López, 2011: 64 y 67).

${ }^{13}$ En este espacio, la palabra enfermarse es manipulada por los miembros y en ocasiones significa indignarse.

${ }^{14}$ Traducción del autor: "To understand the ways in which the social world is constructedand transformed through everyday action” (Escalona, 2016: 250).
}

EntreDiversidades. Revista de Ciencias Sociales y Humanidades, vol. 8, núm. 1 (16), enero-junio 2021. Páginas: 212 - 240 ISSN-e: 2007-7610. https://doi.org/10.31644/ED.V8.N1.2021.A09 
sobre la conformación de un grupo de cuarto y quinto paso: "Roberto y otras personas dijeron: nos va a apadrinar el padrino ${ }^{15}$ de Tuxtla, Mateo. El grupo llamado La Esperanza será el que apadrinará al grupo" (Entrevista con Luis, 2017).

Siguiendo esta idea, cuando los integrantes del grupo decidieron reunirse para constituir y proporcionarle un nombre a la organización - las personas que constituyen un Grupo de Cuarto y Quinto Paso pueden decidir darle el nombre y la forma que deseen — los nombres que ofrecieron para el nuevo grupo (por ejemplo: "Llevados por Dios") fueron producidos a partir del lenguaje que utilizan en este espacio social. Esto es un ejemplo de la manipulación de los lenguajes y de los diversos elementos que construyen. Un miembro indicó que él estuvo en la primera junta que se llevó a cabo para conformarlo, este participó en una actividad que se hizo con el objetivo de elegir un nombre para la organización y fue elegida su propuesta; llevaba el nombre de "Nuevo Atardecer". Así pues, indicó que cuando tomó lugar esta reunión todavía no había ido a la "experiencia espiritual", pero conocía un poco del retiro por un familiar. Por tanto, esta persona usó como referencia lo poco que conocía de la "experiencia espiritual" para proponer el nombre del grupo. A propósito de esto, Appendini y Nuijten (2002) señalan que es importante prestar atención a los entendimientos que las personas le dan a la realidad que los envuelve, ya que esto es fundamental para entender el desarrollo de la organización y las formas de disputas existentes.

En este sentido, este tipo de conocimientos elaborados y reelaborados por los integrantes, consciente o inconscientemente, también influyen sobre la manera en cómo se produce una organización de cuarto y quinto paso, los cuales no son un producto de un modelo terapéutico, sino más bien de múltiples entrecruzamientos de ideas, experiencias, organizaciones sociales, instituciones y otros tipos de fenómenos sociales que a la vez son manipulados por diversos miembros, tomando una forma o diversas formas muy particulares.

Las negociaciones que el grupo Nuevo Atardecer construyó se mantuvieron y transformaron por la interacción social (Appendini y Nuijten, 2002). Estas interacciones jugaron un papel importante para la recomposición del grupo y la producción de diversas jerarquías sociales; es decir, este fue producto de un proceso de establecimiento y reproducción de otros grupos de cuarto y quinto paso. Así pues, la historia muestra una dinámica de rupturas en la conformación de los mismos grupos.

De esta manera, la constitución de un "nuevo" espacio social implicó "nuevas relaciones de poder" (Nuijten, 2005: 8), relaciones sociales que empezaron a producirse a partir de la primera sesión. De hecho, algunos integrantes comenzaron a identificar estas mezclas de discursos y prácticas como signo distintivo respecto a otras organizaciones e instituciones:

Me gusta porque es un grupo como mezclado en todo, mezclado en tu vida, no es como un tradicional de que solo la botella tapan y puedes seguirte drogando, puedes ser mujeriego, puedes hacer mil cosas pero solo el chiste es tapar la botella [...] Yo acudí al DIF [Sistema Nacional para el Desarrollo Integral de las Familias] a una psicóloga, era una mujer y yo no me podía desenvolver, aparte no me gustó esa relación en la que ellos me ponen hacer una actividad, me

\footnotetext{
${ }^{15}$ Persona que ya hizo la "experiencia espiritual".
}

EntreDiversidades. Revista de Ciencias Sociales y Humanidades, vol. 8, núm. 1 (16), enero-junio 2021. Páginas: 212 - 240 ISSN-e: 2007-7610. https://doi.org/10.31644/ED.V8.N1.2021.A09 
seguía sintiendo igual; a uno de Neuróticos Humanos, no me agradó. También acudí a iglesias católicas, el padre no me tocaba temas con el alcohol, drogas o emocionales y sentí que mi problema era otro (Entrevista con Pelón, 2017).

\section{Conflictos, tensiones, distinciones y negociaciones}

De todas las personas que participaron en la fundación del grupo, solamente quedan Roberto y Luis, los cuales me explicaron que los demás se fueron por diferentes motivos. Actualmente, Roberto es la persona que se encarga de organizar la mayoría de las actividades del grupo. Durante mi estancia en el grupo, la membresía cambiaba constantemente, disminuía y aumentaba ${ }^{16}$, debido a que las personas no son estables: se alejan y vuelven por diferentes razones y constantemente hay afluencia de gente. Los motivos por los que llegan son muy diversos: drogas, alcohol o alguna situación personal, entre otros. Los integrantes se mantienen a base de las cuotas que les piden a las y los participantes.

Los conflictos, diferencias, tensiones y negociaciones que hay entre los miembros, durante las reuniones o fuera del grupo, se presentan como parte de las dinámicas de interacción. En las sesiones, los miembros realizan una práctica que para ellos es curativa, la cual consiste en pararse sobre una tribuna ${ }^{17}$ y reconocer verbalmente, frente a los demás, todas las experiencias que tuvieron con el alcohol, las drogas, los problemas emocionales, sexuales, entre otros, para experimentar una especie de "liberación” o "transformación” de su persona.

Estas exposiciones, aparte de ser muy variadas, producen una especie de jerarquía entre las y los participantes, debido al uso que les dan a los discursos. Por ejemplo, los recién llegados, frecuentemente no saben manejar y manipular muy bien los lenguajes de este mundo social, como las y los participantes que llevan meses, ańos o vienen de otras organizaciones. También se puede observar cómo algunos miembros, mientras están verbalizando sus experiencias en tribuna, emplean diversas expresiones orales y mímicas: el tono de voz fuerte o los gritos son utilizados para asustar a los demás; el sarcasmo sirve para comunicar algún malestar con otro integrante u organización; las caras alegres, tristes y enojadas, hasta las miradas fijas, son empleadas como tácticas para lograr algún fin, así como el golpear la tribuna con la mano y seńalar con un dedo a una persona. Así pues, se puede apreciar de distintas formas el efecto que tienen sobre la audiencia algunos oradores: caras sonrientes o conmovidas por los discursos, sobresaltos al oír que alguien le pega con la mano a la tribuna, carcajadas y aplausos estruendosos. Aunque no siempre es así, porque en algunas ocasiones las personas que están exponiendo llegan a aburrir a la membresía, molestar e irritar; en ocasiones los oyentes no ponen atención, ya que se encuentran mirando, a cada rato, el reloj o el celular. Todas estas interacciones producen diversos tipos de reconocimiento sobre los integrantes — por ejemplo, los que saben manejar los discursos y hacen reír a la audiencia, a veces llegan a tener mayor popularidad—, así como estrategias persuasivas o de intimidación.

\footnotetext{
${ }^{16}$ La membresía era de seis hasta más de 22 participantes. Esto variaba, debido a que en ocasiones se hacían aniversarios para festejar el número de años que una persona tenía en la agrupación, el recibimiento en el grupo de las personas que iban a los retiros — a estos eventos asistían sus familiares o conocidos—, también cuando asistían personas de otras organizaciones.

${ }^{17}$ Esta categoría es parte del lenguaje de los miembros.
}

EntreDiversidades. Revista de Ciencias Sociales y Humanidades, vol. 8, núm. 1 (16), enero-junio 2021. Páginas: 212 - 240 ISSN-e: 2007-7610. https://doi.org/10.31644/ED.V8.N1.2021.A09 
Para enfrentar los conflictos, tensiones y distinciones e increpar a los demás, los miembros han reproducido diversas estrategias de negociación (consciente o inconscientemente) para evadir diversos mensajes de regulación (o intentos de control) y seguir en el grupo, que incluyen un lenguaje rudo, violento y directo. Como ejemplo, "antes de llegar al grupo vi a un miembro que estaba fumándose un cigarro, me acerqué y me dijo que él seguía fumando por la ansiedad a la droga y estaba escondiéndose para que los padrinos no lo vieran y le llamaran la atención" (Diario de campo, 2017), ya que los padrinos dicen: "Todo o nada", es decir, dejar de consumir totalmente alcohol, drogas o cigarros u otras sustancias tóxicas. Así, a este respecto, dice Nuijten: "Si bien es cierto que en términos formales la mayoría de las organizaciones se definen en términos de objetivos colectivos, en realidad los diferentes miembros de una organización a menudo tienen diferentes objetivos e intereses" (2005: 4); como vemos, algunos integrantes llegan al grupo, a veces, para remediar alguna situación específica, pero no están de acuerdo con dejar otros hábitos.

Varios integrantes manifiestan que en este lugar, dado que todos son iguales, son aceptadas las diferentes formas de pensar y creencias religiosas, y que la entrada al grupo está abierta para cualquiera, pero con esto se trata de dar una apariencia de unidad, debido a que en este espacio se observan distinciones, conflictos y tensiones por parte de todos los involucrados. Al ser un grupo donde las y los participantes pueden "optar" por ciertos "servicios" y mostrar una especie de unanimidad, se produce un conflicto por compartir el poder. En este sentido Coser señala una de las opciones que tienen los grupos sectarios en cuanto a las contradicciones del poder: "desarrollar estructuras burocráticas que, al implantar en la práctica la desigualdad, niegan la igualdad teórica que postulan; además, uno de los principios organizativos opuestos: un tipo de estructura en cuyo seno todos son generales y existe siempre el peligro de un pronunciamiento" (1978: 110). Mi objetivo no es definir si esta organización es una secta o no, pero en el transcurso de la investigación no pude evitar darme cuenta de que se ven algunas similitudes entre las sectas y este tipo de organizaciones.

Al finalizar algunas reuniones el coordinador normalmente señala: "Lo que aquí se dice, aquí se queda”, con el fin de que no se divulgue lo que expresa algún miembro en tribuna, su nombre o que esta persona se encuentra integrada en el grupo. Aunque afuera de este los integrantes hablan de lo que externaron sus compañeros y compañeras, de la misma forma rumoran detalladamente las relaciones de conflicto, de amistad y amorosas que sostienen entre ellos.

\section{Jerarquía social del grupo Nuevo Atardecer}

En el espacio del grupo Nuevo Atardecer también se ha producido una especie de jerarquía social, aunque sin orden jerárquico tradicional, es decir, en este lugar no siempre los líderes son seguidos, idolatrados u obedecidos, sino que, por el contrario, llegan a tener menos popularidad que los demás; a veces, las personas externas a la organización son más admiradas que los cofundadores. La conformación de la jerarquía está compuesta por diversas categorías de diferenciación de miembros —nuevo, madrina, padrino, líder o guía espiritual—, las cuales son reinterpretadas, manipuladas y usadas como vehículos para disputarse el prestigio (ser padrino, por ejemplo, es una práctica que lo otorga) y la autoridad (coordinar las juntas diarias, la "experiencia espiritual” y las juntas de trabajo).

EntreDiversidades. Revista de Ciencias Sociales y Humanidades, vol. 8, núm. 1 (16), enero-junio 2021. Páginas: 212 - 240 ISSN-e: 2007-7610. https://doi.org/10.31644/ED.V8.N1.2021.A09 
Las personas que dominan los "saberes" emocionales les hacen saber a los "nuevos", de una manera violenta y directa, que son portadores de una "enfermedad emocional y física": "Nos convertimos en alcohólicos y drogadictos porque somos culeros y estúpidos" (Diario de campo, 2017). Los recién llegados son vistos como "ignorantes y estúpidos"; como seres que al no saber vivir "correctamente" abusan del alcohol, las drogas y tienen "problemas" emocionales. De ahí que, los padrinos, al usar diversos discursos que son desconocidos para los nuevos, intentan aventajarlos, puesto que creen estar en una posición que les permite incitar a los recién llegados para que vayan al retiro espiritual a "abrir los ojos", esto es, que se den cuenta que tienen diversos conflictos con el alcohol, los cigarros, las drogas, las emociones, las personas y demás. De esta forma, se instituyen y acreditan a los denominados padrinos, madrinas, líderes y guías espirituales para funcionar como artefactos indispensables de salvación para los nuevos.

Pero, ¿cuál es el proceso que tienen que realizar los nuevos para transitar al estatus de padrino o madrina y adquirir estos saberes emocionales? Se ejemplificará esto a través de la etnografía realizada en la "experiencia espiritual" que realizó el grupo Nuevo Atardecer de cuarto y quinto paso.

Para ir a la "experiencia espiritual" te citan a las ocho de la mañana en el local, con lonche y sin celular; Roberto dijo que este aparato no lo necesitaríamos. El retiro tiene un costo de trescientos cincuenta pesos por persona, porque señalan que es para los gastos de la gasolina y la comida. Después te hacen rellenar y firmar un documento [nunca averigüé si el documento fue elaborado por los integrantes] que contiene datos personales como: nombre, edad, sexo, número de teléfono, dirección y apelativos de los progenitores. Además, en el formulario se le denomina a la "experiencia espiritual" como una "acción terapéutica" en la cual se va a encontrar a Dios; al final del documento se indica que ellos se deslindan de las posibles consecuencias que lleguen a surgir, por ejemplo: un trastorno mental, muerte u otro tipo de lesiones.

Más tarde, nos fuimos en el carro de los organizadores y al llegar a la localidad nos dejaron esperando alrededor de tres horas, custodiados por dos padrinos; supe que durante ese tiempo algunos integrantes fueron a preparar el terreno para la "experiencia espiritual". Este era un terreno baldío donde se colocaron unas carpas: una para meter a los escribientes, otra para la cocina y una más (denominada capilla) para que los integrantes realicen rezos. En las juntas de preparación nos habían mencionado que, a partir de las dos de la tarde, la comida iba por parte de ellos, pero ya estando ahí nos dijeron que ya no íbamos a comer (fue un engaño lo de la comida), ni a dormir hasta el próximo día; algunas personas llevaban maleta, creo que pensando que iban a dormir.

Cuando vinieron por nosotros nos llevaron en fila hasta una carpa; luego, nos metieron, y observé una mesa con cuatro sillas, encima había cuatro hojas y cuatro plumas; posteriormente, nos sentaron y probaron el agua que traíamos para verificar que estas no estuvieran mezcladas con azúcar, una botella tenía bebida de sabor dulce, así que la tiraron y la rellenaron con agua; después nos sacaron de la carpa uno por uno para revisarnos y ver que no habíamos escondido celulares, comida o algún tipo de droga.

EntreDiversidades. Revista de Ciencias Sociales y Humanidades, vol. 8, núm. 1 (16), enero-junio 2021. Páginas: 212 - 240 ISSN-e: 2007-7610. https://doi.org/10.31644/ED.V8.N1.2021.A09 
Asimismo, mientras el coordinador se presentaba (como alcohólico y enfermo emocional) y caminaba alrededor de la mesa nos comenzó a decir que el trabajo iniciaba: las buenas palabras y amabilidades se habían terminado y ahora estas “¡chingaban a su madre!”, que íbamos a escribir las cosas como son: "jal pene le vamos a decir verga, a la vagina panocha, nada de decir me introdujo el pene, es: el hijo de su pinche madre me cogió, me metió la verga!"; de esta forma es como teníamos que anotar. Caminar alrededor de la mesa mientras se cuentan las experiencias que tuvieron los integrantes con el alcohol, drogas o un problema emocional es denominado por las y los participantes del grupo como "pasarela", esta es una de las actividades principales que hacen los padrinos y madrinas, para que el iniciador se identifique con ellos. Durante la presentación las madrinas y padrinos se definen como alcohólicos, drogadictos, enfermos emocionales, trastornados, lujuriosos o codependientes.

Antes de iniciar el trabajo de escritura, el coordinador les dice a los iniciados que "aquí no se etiqueta a nadie" y así, escuchando los historiales de los demás miembros, se darán cuenta de qué problema o "enfermedad" adolecen. Terminado esto comenzaron a dictarnos las preguntas: "Mirando el pasado ¿Puedo darme cuenta cómo, cuándo y dónde se descoyuntó mi instinto sexual y qué fue lo que sentí: miedo, ansiedad o frustración? ¿Actualmente qué tipo de situaciones sexuales me causan miedo, ansiedad o frustración? ¿Actualmente qué tipo de situaciones me causaron miedo, ansiedad o frustración en el aspecto material y emocional? ¿En el aspecto social qué tipo de situaciones me causaron miedo, ansiedad o frustración? ¿Resentimientos? ¿Actualmente qué tipo de situaciones me causan asco y repugnancia de mí mismo?". A continuación, pasaron los llamados padrinos para contarnos sus experiencias en relación con las preguntas, expresándose con un lenguaje altisonante nombrado por ellos como "lenguaje alcohólico". En esta parte traté de recordar acontecimientos de mi vida para contestar las preguntas, debido a que tenía curiosidad por saber qué es lo que pasaría después de la "experiencia".

Cuando terminó la cuarta pregunta nos dijeron que dejáramos de escribir e iniciaron los ejercicios; el primero fue el llamado de "proyección": consiste en sacar de la carpa con los ojos cerrados a los escribientes y llevarlos por separado a un lugar alejado de esta para arrodillarlos, luego, ponerles un tubo, de madera o plástico, en la mano y se les pregunta: “¿Quién te hizo daño o a quién dañaste?". Esto para sacar el "dolor" o "resentimiento" y pedir el perdón a Dios por las personas que dañamos y nos dañaron. Posteriormente, nos señalan que teníamos que "matar" a las personas, "dejarlas" o "enterrarlas ahî", por medio de decir en voz alta sus nombres y los mandáramos a "chingar a su madre" o manifestar "chinga tu madre por todo lo que me hiciste”. Mientras, algunos integrantes nos expresaban: “Déjalos aquí, entierra a ese/a hijo/a de su pinche madre, mátalos o mátalas porque te hicieron daño las hijas de su pinche madre, diles que chinguen a su madre todos y saca tu dolor, entiérralos!".

De esta forma se espera que las y los participantes puedan alcanzar una "recuperación" o "liberación” del alcohol, drogas o problemas emocionales. Durante el ejercicio, me percaté que ellos esperaban que yo sollozara, no lo hice; más adelante me di cuenta de que el "llorar" para algunos integrantes es una forma de "arrepentimiento" y de ser una persona "humilde". Después

EntreDiversidades. Revista de Ciencias Sociales y Humanidades, vol. 8, núm. 1 (16), enero-junio 2021. Páginas: 212 - 240 ISSN-e: 2007-7610. https://doi.org/10.31644/ED.V8.N1.2021.A09 
de otra pregunta nos sacaron una vez más y al término de estos ejercicios acabé con ampollas en las manos, ya que le tenía que pegar al suelo con todas mis fuerzas, al igual que varios de los y las participantes.

Al finalizar las preguntas entró el coordinador a la carpa cargando en su mano un plato de chiles en vinagre. Nos dijo que agarráramos uno, la mayoría tomó, pero yo les comenté que no quería porque había tomado café y a veces esta combinación no me caía bien en el estómago, ellos me dijeron que eso era no ser "humilde" y si no agarraba nos quedaríamos más tiempo, hasta el lunes, así que tuve que comer una zanahoria, no porque yo quisiera ser "humilde", sino para complacerlos. Así pues, nos dieron una torta de frijoles con mayonesa y nos dijeron que como nunca habíamos "valorado" algo ahora lo íbamos hacer.

De igual forma, cuando termina esta actividad cada uno quema la libreta que utilizó para el trabajo, y después el padrino grita: ¡ha nacido un nuevo padrino o madrina! $\mathrm{O}$ un "nuevo bebé". Se me hizo pesado estar por más de diez horas en una silla, escribiendo y sin dormir. Al finalizar la "experiencia" me dio un ataque de pánico, tenía temores y ansiedad. Pasados unos días, estando en la calle, tuve otro ataque de pánico; no sé si el retiro haya tenido algo que ver (Diario de campo, 2017).

Para tener el estatus de "madrinas" o "padrinos", los recién llegados tienen que atravesar por este proceso. Al terminar, se espera que estos ya no vuelvan a consumir drogas, alcohol o a tener dificultades emocionales, pero si vuelven a reincidir en algún aspecto serán descalificados por sus compañeros: "son una mierda las personas que van a la 'experiencia' y vuelven a recaer" (Diario de campo, 2017). También, los padrinos que llevan años en el grupo y tienen un resbalón son desacreditados por los demás: "Luis decía que ellos (los padrinos) estaban para ubicar a la gente y a los "pendejos padrinos" (Diario de campo, 2017). Los padrinos "recuperados" (que no tienen ningún resbalón) creen que se encuentran en un nivel socialmente diferente al de los otros integrantes, por lo que su estatus conlleva a comportarse con los demás de una forma distinta. Estas situaciones producen ciertas diferenciaciones entre los miembros, de padrino "descarriado" a uno "recuperado", y se limitan a erigir un muro simbólico.

Los "líderes" o "guías espirituales" son los que fundan un grupo. Estos deben de tener una serie de cualidades, por ejemplo, que sea hombre, tenga liderazgo nato, poder de convocatoria y mayor experiencia en grupos de cuarto y quinto paso. Además, cuando se nombra a un líder, este ya no podrá ser desplazado de su posición, se deberá respetar y obedecer, debido a que esta autoridad es puesta por Dios. Al menos, eso es lo que dice el "primer manual de servicios" de los grupos de cuarto y quinto paso (Castro, 2000). Algunos integrantes esperan que estas personas sean rectas y espirituales.

En el grupo Nuevo Atardecer, Roberto y Luis, por ser cofundadores, son considerados por varios miembros como líderes. Roberto coordina las "sesiones diarias", las "juntas de inducción" y la "experiencia espiritual". Lleva varios años sin consumir alcohol, sabe manejar los lenguajes y las prácticas; es seguido y adulado por diferentes miembros, pero por otros es criticado y odiado. Luis está bajo el mando de Roberto, ya que este le señala lo que tiene que hacer en las "experiencias espirituales" (aunque Luis no siempre sigue las reglas de este). También Luis

EntreDiversidades. Revista de Ciencias Sociales y Humanidades, vol. 8, núm. 1 (16), enero-junio 2021. Páginas: 212 - 240 ISSN-e: 2007-7610. https://doi.org/10.31644/ED.V8.N1.2021.A09 
es idolatrado por algunos integrantes, ya que lo consideran una persona con convicciones religiosas muy fuertes, aunque otros piensan que es un fanático religioso.

Mientras más participen los padrinos y madrinas en las sesiones diarias y la "experiencia espiritual", van adquiriendo un mayor manejo de los diversos discursos de este mundo social. Varios integrantes, al usar muy bien los discursos, son considerados como personas que tienen más experiencia y conocimiento en cuanto a diferentes aspectos de la vida. Es más, llegan a ser invitados por parte de otros grupos a compartir algún tipo de tema. Así pues, se les concede una especie de autoridad, distinción y prestigio ante los demás.

Los diversos lenguajes ${ }^{18}$ (discursos médicos, religiosos y psicológicos) que se despliegan en este espacio transfiguran las relaciones de poder, esto es, categorizan y clasifican a los integrantes, dando como resultado una producción jerárquica. Esta es parte de las distintas dinámicas de interacción social que se producen en el grupo. En la mayoría de las organizaciones se pueden encontrar formas de luchas, diferenciación y distinciones entre desiguales categorías de personas (Nuijten, 2005).

El grupo Nuevo Atardecer mantiene relaciones sociales con otras organizaciones a pesar de que no están de acuerdo con su forma de operar (anexos y Alcohólicos Anónimos), ya que consideran que los métodos utilizados por otras asociaciones son "estériles". Los integrantes, intentan distinguirse y relegar a las organizaciones e instituciones que no están en sintonía con el lenguaje que ellos utilizan sobre una "enfermedad emocional". Por consiguiente, Roberto, Luis y otros miembros de más tiempo no quieren que las y los participantes vayan a otros grupos, debido a que ellos afirman que no son tan eficaces como su agrupación.

Estas interacciones llegan a producir, en ocasiones, conflictos entre miembros y forasteros. Por ejemplo, en una ocasión Roberto no entró a la sesión y se regresó a su casa, debido a que él manifestó que antes de entrar vio que estaba exponiendo una persona (que venía de un anexo) que no era de su agrado. Debo agregar que esta persona exponía de una forma muy coherente y bromista.

Por último, esta organización tiene un interés en mantener una posición privilegiada frente a las demás, mediante la incorporación de diferentes elementos de otros grupos, instituciones y programas para reforzar su poder simbólico. Los discursos que se despliegan en este espacio social son utilizados, manipulados y reproducidos por algunos integrantes para ciertos fines, dándoles sus propias significaciones al mundo social que construyen. La mezcla de lenguajes (médicos, religiosos y psicológicos), las prácticas y representaciones del grupo han originado una configuración en las relaciones sociales y el establecimiento de una jerarquía.

\footnotetext{
${ }^{18}$ En otro ensayo me dedicaré a tratar más detenidamente los lenguajes de poder que se despliegan en el grupo Nuevo Atardecer.

EntreDiversidades. Revista de Ciencias Sociales y Humanidades, vol. 8, núm. 1 (16), enero-junio 2021. Páginas: 212 - 240 ISSN-e: 2007-7610. https://doi.org/10.31644/ED.V8.N1.2021.A09
} 


\title{
Lenguajes metaforizados
}

\author{
El fracaso es huérfano y el éxito tiene muchos padres, pero yo vi \\ y me consta que Nacho Q. fue la persona que Dios escogió para ser \\ el primer líder de esto (Castro, 2000).
}

Los integrantes del grupo Nuevo Atardecer de cuarto y quinto paso utilizan diferentes "lenguajes de poder", que dominan en los escenarios donde se desarrollan las actividades del grupo (sesiones, "experiencia espiritual" y junta de trabajo), para remarcar las diversas formas de representar el mundo social (Escalona, 2012). A partir de este entienden su abuso del alcohol y de las drogas, así como sus conflictos emocionales, como causa de una "enfermedad emocional y física"; de tal manera, tratan de explicar su padecimiento e ideas del origen del mismo para "curar", "recuperar" o "liberar" a las personas de estas dolencias, visibilizándose esto en las prácticas rituales, las cuales se entreveran con otro tipo de convicciones.

Parte de los lenguajes que se despliegan en este espacio social están formados por categorías y significados que, al mismo tiempo, se encuentran mezclados con otros tipos de "lenguajes metaforizados" (psicológico, religioso y médico). Por lenguaje metaforizado me refiero al sentido de algunos términos que parecen específicos de alguna ciencia, por ejemplo "enfermedad", y que las personas han cambiado, otorgándoles un significado particular, el cual es manipulable por los mismos.

Desde los inicios de la constitución de estos grupos, algunos miembros produjeron este lenguaje "mítico" sobre el surgimiento de la agrupación, el cual les permitió comunicar e instaurar un "medium simbólico"19 (Bourdieu, 2006) que les hizo posible elaborar significaciones y un entendimiento del mundo social que construyeron (cambiante y contradictorio) a través de una mezcla de lenguajes médicos, religiosos, psicológicos y puntos de vista de la vida íntima; por ejemplo, un integrante mencionó durante una reunión que la "neurosis" es una enfermedad que necesita cura a través de la "experiencia”, y esta experiencia es 100\% "espiritual". Ahora siguen reproduciéndolo, pero mezclándolo con otros tipos de discursos. Esto dio como resultado la aparición de los grupos de cuarto y quinto paso, el despliegue de la llamada "experiencia espiritual", las prácticas de "curación” y la conformación de un mundo social con sus múltiples contradicciones.

De esta suerte, los primeros integrantes de los grupos de cuarto y quinto paso que participaron en un grupo de AA siguen reproduciendo los lenguajes que recogieron de esta organización, pero se han ido manipulando, cambiando y ańadiendo distintos elementos discursivos, procesos que dependen de diversas variables. Así, la multiplicidad de lenguajes mezclados, no profesionales ${ }^{20}$,

\footnotetext{
${ }^{19}$ Con este término Bourdieu se refiere a la utilización de la religión como una lengua; esta es un instrumento de comunicación y conocimiento estructurado y estructurante. También tiene la posibilidad de consensar un sentido de los signos y del mundo que permiten edificar.

${ }^{20}$ Con lenguajes no profesionales me refiero a términos que no se consideran propios de una ciencia (médicos, psicológicos, entre otras ciencias).
}

EntreDiversidades. Revista de Ciencias Sociales y Humanidades, vol. 8, núm. 1 (16), enero-junio 2021. Páginas: 212 - 240 ISSN-e: 2007-7610. https://doi.org/10.31644/ED.V8.N1.2021.A09 
del grupo Nuevo Atardecer provienen de reinterpretaciones, por parte de cada participante, de otros tipos de discursos que se generan en los entrelazamientos de organizaciones e instituciones, producto además de interacciones de varios años que los miembros han tenido con infinidad de gente, tanto dentro como fuera de la organización. De esta manera, la producción y reproducción de los lenguajes se puede percibir en las narrativas de los integrantes. Los y las participantes al escuchar las diversas experiencias de vida han generado un escenario en el cual se negocia y constantemente se encuentra en tensión.

Los miembros utilizan de manera asistemática estos lenguajes para explicar su padecimiento: "Roberto señaló que nos enfermamos de cáncer, gastritis y azúcar por las emociones: la 'experiencia espiritual' nos libera y nos levanta la autoestima" (Diario de campo, 2017); construir ideas del origen del mismo: "sólo Dios sabe por qué estoy enferma de la ciática, hay algo que tengo que pagar. Siempre le he estado pidiendo perdón por lo malo que he hecho y le doy gracias a Dios por mi enfermedad" (Entrevista con Rosario, 2017); y producir efectos en los y las participantes: "la 'experiencia espiritual' cambió mi forma de pensar y de sentir" (Entrevista con Julieta, 2017). De este modo, se justifica la permanencia del grupo Nuevo Atardecer y de la práctica curativa denominada la "experiencia espiritual". Como explica Escalona: "estas mezclas de diversas fuentes discursivas en el lenguaje y los múltiples usos de esas palabras no constituyen sólo una retórica vacía o inocua; por el contrario, son parte del proceso de reflexión sobre el mundo, parte también de los diálogos y de las formas en que se produce la acción...” (2009a: 43).

De este modo, el componente religioso es utilizado por algunos integrantes para interpretar un mundo social divino - Roberto dijo que después de una "experiencia” de hace ya seis años regresó sintiéndose un santo: "ni siquiera quería tocar a mi mujer porque para mí significaba un pecado" (Entrevista con Roberto, 2017)—; o también para justificar la continuación de la organización — Roberto tuvo una revelación, mientras estaba adormilado, vio a Jesús con una corona de espinas. Después le contó esto a otra persona y esta le dijo que él era un hijo privilegiado de Dios-. De esta forma se establece una jerarquía en el grupo: los que dicen ser "privilegiados" o "escogidos" de Dios y los seguidores. Estas ideas se perciben en las narraciones de los integrantes y han adquirido significado, pero al mismo tiempo proporcionaron un fundamento para que un "lenguaje hable sobre el poder"21 (Escalona, 2008: 566).

Los lenguajes psicológico y médico distinguen a la agrupación de otras organizaciones y construyen la percepción de un mundo social constituido por personas que se encuentran "enfermas" del alcohol, las drogas y las emociones por causa de una enfermedad emocional y necesitan ser salvados: "Aquí me hablaban de la drogadicción, de mis emociones y neurosis, me invitaron al grupo para salirme de mi enfermedad. Cuando llegué al grupo solo me calificaba como borracho o como alcohólico, más nunca dije los problemas que tenía adentro" (Entrevista con Pelón, 2017).

Estas vivencias sirven también para producir una serie de categorías que siguen siendo reproducidas a partir de los lenguajes y transmitidas a los escribientes. Así, las personas son interpeladas por estos lenguajes; de alguna manera los aceptan, admiten que están enfermos, tienen problemas, están mal, necesitan el grupo y a la "experiencia espiritual”. En este sentido, Escalona menciona:

${ }^{21}$ Traducción del autor: "Language to talk about power" (Escalona, 2008: 566).

EntreDiversidades. Revista de Ciencias Sociales y Humanidades, vol. 8, núm. 1 (16), enero-junio 2021. Páginas: 212 - 240 ISSN-e: 2007-7610. https://doi.org/10.31644/ED.V8.N1.2021.A09 
Los discursos nunca son reproducción simple o copia directa de aquellos de donde se adquieren; tampoco implican un desplazamiento total de discursos y lenguajes previos; y finalmente, no todos adquieren un mismo nivel de influencia en las vidas de las personas, surgiendo así formas discursivas de uso estratégico al lado de otros que producen sentidos más elementales en la vida cotidiana, como ontologías (es decir, teorías locales del ser) que no se expresan como filosofías o cosmovisiones ordenadas, sintéticas ni sistemáticas, sino más bien como formas de experimentar el mundo en la práctica y en el discurso, con espacios también ambiguos e inciertos (2009a: 41).

Por medio de estos lenguajes se pueden percibir diferentes formas de entender el mundo; a pesar de que los integrantes han adquirido ciertas categorías de este espacio, no todas son usadas con el mismo significado, debido a que estas pueden ser manipuladas. Asimismo, no todos los y las participantes que retornan a la organización es porque aceptan o piensan que están enfermos, sino más bien porque creen que un familiar sí lo está.

Por ende, los lenguajes contribuyen a la formación de diversas prácticas y de entendimientos, generando la construcción de una estructura de pensamiento y percepción del mundo social (Bourdieu, 2006); esto es, un mundo que está enfermo y necesita ser salvado, el cual se engendra con palabras y significados previos pero negociables. Dichos significados los miembros los interpretan, malinterpretan o reinterpretan mediante las palabras, y los juegan de una manera distinta. Lo que se percibe entonces de los conflictos cotidianos son lenguajes mezclados y cambiantes que producen "visiones contradictorias y ambiguas del mundo social" (Escalona, 2009a: 41).

Además, los integrantes llegan a utilizar varias tácticas poderosas como la culpa, la vergüenza, el miedo, la humildad, la enfermedad y el castigo espiritual, mezclándolas con relatos sobre la familia y la violencia sexual, todo ello con el fin de que la persona se doblegue, acepte una enfermedad y reconozca que necesita ser salvada del sufrimiento, de los daños que ha hecho o que le hicieron, así como ser guiada por un integrante que ya haya realizado el retiro espiritual. De esta forma varios integrantes repararán en por qué es tan importante la "experiencia espiritual".

Sin embargo, no siempre estas tácticas llegan a ser eficaces o a tener un efecto inmediato, puesto que diversos miembros, para contrarrestar este ataque, utilizan un "doble discurso" para expresarle al "agresor" — que puede ser el fundador del grupo u otros/otras participantes — su inconformidad o sus equivocaciones. Este "doble discurso" consiste en hablar de una forma general de sus historias de vida, pero esta exposición va camuflajeada y dirigida hacia el oponente, para comunicar qué debe hacer con su vida, qué está haciendo mal en su cotidianidad y señalarle sus errores; es denominado por los integrantes como "tirando piedras"22.

\section{Produciendo la enfermedad}

La “experiencia espiritual” se analizó y comprendió como una producción simbólica de los "lenguajes de poder" (Escalona, 2012), constructora asimismo de percepciones de un mundo social enfermo de las emociones, en el que existen distinciones entre la persona recuperada y enferma, y se generan sentidos contradictorios a través de un sistema impreciso de prácticas.

${ }^{22}$ Normalmente esta frase la dicen los integrantes cuando una persona está hablando de ellos.

EntreDiversidades. Revista de Ciencias Sociales y Humanidades, vol. 8, núm. 1 (16), enero-junio 2021. Páginas: 212 - 240 ISSN-e: 2007-7610. https://doi.org/10.31644/ED.V8.N1.2021.A09 
Es decir, la organización de algunas "experiencias espirituales" muchas veces no fue, desde luego, programada. Esta práctica tiene cuatro momentos: primero, las juntas de "inducción" o "preparación" ${ }^{23}$; segundo, el retiro espiritual; tercero, el "recibimiento"; y por último, el "devolver". Al pasar por este proceso, se espera que las personas se den cuenta del tipo de enfermedad que padecen.

La práctica curativa de la "experiencia espiritual" opera de diversas formas; entre ellas, funge como una especie de "máquina de hacer enfermos". En el proceso, esta práctica "agarra" a los escribientes por su lado más débil ${ }^{24}$. Después de esta experiencia, varios de estos enfermos, al asumir su condición como tal, parece que están prestos a ser manipulados con mayor facilidad. Algunos participantes entran buscando una respuesta, pero esta es la construcción de una enfermedad, aunque no siempre sea la misma ni discurra de iguales modos. Además, hay una gran cantidad de juegos inconscientes en las personas que se involucran en estos espacios. Las personas que entran a estos escenarios no solamente entran en juegos de poder, sino a un mundo donde existen una serie de miedos, de prejuicios y de visiones de lo que es la persona.

Durante la "experiencia espiritual" se intenta hacerle creer a algunas personas que son portadoras de una enfermedad, pero en este espacio también se pueden observar las contradicciones de los y las participantes, los que no se consideran enfermos y los que sí, los que mienten o fingen ser enfermos, etcétera. Hay varias personas que asisten al grupo y no se consideran alcohólicas. Una de las integrantes me dijo que en el grupo tenía que presentarse como alcohólica, aunque ella no se considerara así; es en ese escenario donde les hacen saber a los miembros que por haber bebido una sola cerveza ya son alcohólicas o alcohólicos: "Yo ya tenía siete años que no bebía, sí tomaba pero poco, una cerveza. Yo no vine por el alcohol, vine por la depresión, por la codependencia y la tristeza, ya estaba cansada de sufrir" (Entrevista con Martha, 2017). Los lenguajes actúan sobre el sentido del mundo social de una forma diferente y diversa, producen un ideal y un lenguaje repleto de contradicciones y mezclas (Escalona, 2009).

También pude percibir que no todos los integrantes, a pesar de que están en el grupo, se consideran enfermos emocionales o físicos, tal y como me lo dijo Romeo: "Yo no me considero alcohólico, ni drogadicto, no tengo problemas de eso. Tampoco adicción al tabaco. Cuando voy al grupo resultó que era neurótico, pero yo no sufro de problemas emocionales". Otros integrantes mienten cuando se identifican con alguna enfermedad en el grupo, por ejemplo el caso de Lupe, porque no se consideran enfermas o enfermos, de esta forma negocian su permanencia.

Por otra parte, la "experiencia espiritual" o retiro espiritual que realiza el grupo Nuevo Atardecer es diferente al que hacen otros grupos, debido a que en esta solamente hacen cinco días de juntas de inducción; el retiro se realiza una vez al mes y tiene una duración de aproximadamente dos días. Salen el sábado a las ocho de la mañana y regresan el domingo alrededor de las cinco de la tarde. El fundador del grupo manifestó que solamente tiene una duración de dos días la "experiencia espiritual", pues "era menos cansado hacerlo de pocos días".

$\mathrm{Al}$ comienzo y durante la "experiencia espiritual", el coordinador y otros integrantes constantemente manifiestan el tipo de enfermedad que padecen y cómo a través del retiro se

\footnotetext{
${ }^{23}$ Son nombradas así por los integrantes del grupo.

${ }^{24}$ Agradezco a Noelia Soledad López por aportarme estas ideas.
}

EntreDiversidades. Revista de Ciencias Sociales y Humanidades, vol. 8, núm. 1 (16), enero-junio 2021. Páginas: 212 - 240 ISSN-e: 2007-7610. https://doi.org/10.31644/ED.V8.N1.2021.A09 
dieron cuenta de la misma, esto para que los iniciados puedan identificar el problema que tienen. Pero, al parecer, estas situaciones muestran cómo los integrantes desde un principio dan por sentado que las personas que están ahí se encuentran enfermas, de este modo los enfermos que "ya han abierto los ojos" solamente tienen que revelarles el camino desconocido a los recién llegados: hacia su "verdadera enfermedad". Es decir, en el sentido que alude Lévi-Strauss: "el médico proporciona el mito y el enfermo cumple las operaciones” (1987: 224).

La semántica de las preguntas y la incertidumbre que generan en varios de las y los participantes son parte de este complejo que sirve, con antelación o durante el retiro espiritual, a los integrantes del grupo como táctica para intentar infundir "temor" en los escribientes. Por ejemplo, Rosario decía: “Cuando escuché la primer pregunta ${ }^{25}$ la vi muy difícil, dije: ‘Qué raro que estén preguntando eso!'. Me puse a pensar muchas cosas, porque la mayoría eran hombres. Yo pensaba otras cosas de la 'experiencia' menos eso, me dio miedo [...] hay preguntas que sí duelen" (Entrevista con Rosario, 2017). No obstante, estos intentos de regulación no siempre cumplen con su propósito, debido a que no en todas las ocasiones llegan a provocar ese "temor" sobre los y las participantes: "Me hablan de la famosa 'experiencia' y decían que estaba chingona. Yo nunca le tuve miedo y decidí ir por curioso” (Entrevista con Romeo, 2017).

Los miembros del grupo Nuevo Atardecer representan escenas dramáticas, donde ellos mismos son los actores con un rol muy eficiente, puesto que utilizan sus experiencias pasadas de una forma rememorativa que les permite escenificarlas (Goffman, 2012), todo ello con el fin de incitar a una transformación orgánica y que la persona experimente profundamente un mito, el cual ha sido producido (Lévi-Strauss, 1987). Durante estas actuaciones, que toman lugar en las "pasarelas", los integrantes deben aguantar de pie alrededor de ocho horas; se observan y escuchan gritos, llantos, golpes en la mesa, vociferaciones y lamentaciones.

En algunas prácticas (como el "tornillo") algunos miembros buscan la forma de someter a los recién llegados para que se postren ante Dios, por ejemplo, los agarran y aprietan fuertemente del cuello para que se arrodillen, debido a que creen que es el punto en el cual los iniciados se van a transformar. El poder transformador de esta situación se debe a la capacidad de ciertos acontecimientos que se presentan en un contexto pertinente: histórico, psicológico y social para incitar una objetivación afectiva (Lévi-Strauss, 1987). Asimismo, un acercamiento más minucioso a este espacio social nos muestra cómo las y los participantes colaboran en la reproducción de las prácticas curativas, las cuales no son sistemáticas, ni tampoco reproducidas por un acuerdo en común. Lo que encontramos aquí es un espacio sin orden en donde las personas, circunstancias y demás colaboran en esta reproducción. La organización en su conjunto se puede entender entonces como un "vehículo de producción de sentidos en las condiciones sociales actuales y no sólo [...] formas de organización social repetidas en el tiempo, con sentidos unívocos e inalterados" (Escalona, 2012: 549).

De igual forma, los integrantes del grupo Nuevo Atardecer intentan controlar el tiempo de cada ejercicio que realizan en la "experiencia espiritual”. Pero difícilmente lo pueden lograr, porque a veces se presentan situaciones inesperadas, por ejemplo, el clima o la condición física

\footnotetext{
${ }^{25}$ ¿Puedo darme cuenta cómo, cuándo y dónde se descoyuntó mi instinto sexual y qué fue lo que sentí: miedo, ansiedad o frustración?
}

EntreDiversidades. Revista de Ciencias Sociales y Humanidades, vol. 8, núm. 1 (16), enero-junio 2021. Páginas: 212 - 240 ISSN-e: 2007-7610. https://doi.org/10.31644/ED.V8.N1.2021.A09 
de las y los participantes que alteran el curso de los ejercicios. Estos incidentes ocurren como los que registró Gluckman "espontánea y fortuitamente” (1958: 9). Los miembros y otras organizaciones "participan de esos rituales, los reinterpretan y les dan sentido, modelan su forma [...] y reinterpretan sus significados" (Escalona, 2012: 549).

Por último, al concluir la "experiencia espiritual" se les da un recibimiento en el grupo a los nuevos padrinos y madrinas. Antes de iniciar la junta el coordinador habla con los convertidos para señalarles cómo va a ser el proceso de la sesión. Cada nuevo se presenta entonces con la enfermedad con la que se identificó al finalizar la "experiencia espiritual":

El primer padrino se presentó ante todos como alcohólico, drogadicto, enfermo emocional y neurótico. Él mencionó que al vivir la "experiencia" se te da el regalo de la transformación; las preguntas que le pusieron le habían llegado y le hicieron reflexionar de todo lo que hacía mal. La segunda se presentó como alcohólica, enferma emocional e histérica; dijo que Dios le dio la oportunidad de cambiar - ella había mencionado durante la "experiencia" que no tomaba mucho y que no era alcohólica-y que era una mala mujer, que quería cambiar y terminó llorando. La tercera se presentó como drogadicta, alcohólica y enferma emocional. La cuarta se presentó como alcohólica, neurótica y enferma emocional; además, dijo que los psicólogos y la religión no le ayudaron. La quinta dijo: "Estoy enferma y nunca pensé que estuviera enferma. Sí, tengo enfermedad, mi madrina encontró mi enfermedad, me dijo "mi enfermedad". Me enseñaron qué enfermedad tengo. Ya sané. Estamos enfermos porque peleamos a cada rato (en relación con su familia). La misa no me sanó”. El último se identificó como alcohólico, drogadicto y enfermo emocional. También dijo que se había ido a transformar y que uno despierta ahí. Asimismo, invitó a las personas que no han ido a la "experiencia espiritual" (Diario de campo, 2017).

Al terminar cada presentación se desarrolla un drama, en el cual cada nuevo padrino o madrina se postra ante sus familiares mientras los integrantes observan, para pedirles perdón por todos los daños causados; prometen cambiar, lloran y los abrazan. Roberto termina diciendo: "Al vivir la 'experiencia' se te da el regalo de transformación". Para Coser algunos sectarios desean "transformar la condición humana de sus semejantes" (1978: 111).

$\mathrm{Al}$ parecer, durante el proceso de la "experiencia espiritual" se intenta "transformar" a los escribientes en condición de enfermos por medio de una dramatización o performatividad, en ocasiones improvisada, por parte de los integrantes ${ }^{26}$. Este proceso no siempre es efectivo: solamente cuenta con cierta eficacia momentánea. Es decir, varias personas llegan al retiro espiritual sin asumir que están enfermas, mas sin embargo, terminan por descubrirlo/reconocerlo; otras, por el contrario, aun después de la "experiencia", no aceptan este estatus de enfermo, o bien fingen tal aceptación.

${ }^{26}$ Aportaciones del Dr. Enrique Eroza Solana.

EntreDiversidades. Revista de Ciencias Sociales y Humanidades, vol. 8, núm. 1 (16), enero-junio 2021. Páginas: 212 - 240 ISSN-e: 2007-7610. https://doi.org/10.31644/ED.V8.N1.2021.A09 


\section{Conclusiones}

Hasta ahora, los estudios sobre los grupos de cuarto y quinto paso se han enfocado en una visión relacional y general en cuanto a una ideología, prácticas terapéuticas y la forma de organizarse. Algunos observan un enfoque holístico en la terapia grupal, otros trabajos los ven como portadores de una ideología de otros grupos (como Alcohólicos Anónimos) y algunos más se centran en la parte enigmática: lo espiritual. En este trabajo, mi intención no fue definir si el grupo Nuevo Atardecer de cuarto y quinto paso es una "institución”, grupo de "ayuda mutua" o una "secta", sino más bien cómo se ha producido y se sigue reproduciendo por medio de las múltiples dinámicas sociales esta organización.

Para algunos autores, el grupo Nuevo Atardecer de cuarto y quinto paso representaría un grupo de "ayuda mutua" que se encuentra aislado y no regulado por las políticas de salud pública del Estado; otros, lo considerarían como una "secta" que atenta contra la psicología y dignidad de las personas. Pero lo cierto es que con el paso del tiempo, los integrantes del grupo han construido, aún así, un mundo social en el que las significaciones funcionan en distintas formas dentro del mismo, son diferenciadas. Las categorías de grupos de ayuda mutua y sectas resultaron ser, en el proceso de mi trabajo, limitadas y estrechas, ya que en este espacio no hay un control social total, ni una ideología en común, ni mucho menos un sistema lineal, sino constantes intentos de regulación social y contradicciones en el proceso de producción social. De la misma forma, utilizar la categoría de "organización" no agota la totalidad, pero esta fue para mí la más apropiada, de acuerdo con los hallazgos en campo.

Los cofundadores del grupo Nuevo Atardecer no poseían un cúmulo de esquemas de pensamiento, ni prácticas sistemáticas con respecto a establecer un grupo de cuarto y quinto paso, sino debido al tiempo que estuvieron en el grupo Revolución y escucharon diversas historias, varios de los integrantes reprodujeron ciertos conocimientos, tergiversados y manipulados, que hablaban sobre una enfermedad emocional y física para constituir la organización. Así fue como concluí que estas expresiones y movimientos no surgieron de un plan predeterminado o brotó de una sola persona, sino de la configuración de diversos entrecruzamientos e interacciones con otros tipos de organizaciones (anexos, Alcohólicos Anónimos y otros grupos de cuarto y quinto paso), así como del intercambio promovido por la llegada de miembros que han estado en otras instituciones u organizaciones.

Siguiendo esta idea, me atrajo más analizar desde la perspectiva de la "etnografía del poder" que se centra en los "lenguajes de poder" (Escalona, 2012), debido a que en este mundo social advertí diversos puntos de vista de la vida íntima que se encuentran mezclados con lenguajes médicos, religiosos y psicológicos, que son utilizados a su vez para explicar los padecimientos de los integrantes, sus causas y su cura. Estos lenguajes siempre tienen un estilo verbal duro, violento y dirigido: "es más ciego aquel culero que no quiere ver que el que en realidad no ve". Además, esto me permitía dar cuenta de los procesos y tácticas de producción del grupo. De este modo, se podría sacar a la luz parte de los diversos elementos que utilizan en este tipo de organización para reproducir su espacio social.

Así, he llegado a inferir que los miembros, al construir un sentido particular del mundo por medio de manipular diversos lenguajes, reprodujeron una especie de práctica principal

EntreDiversidades. Revista de Ciencias Sociales y Humanidades, vol. 8, núm. 1 (16), enero-junio 2021. Páginas: 212 - 240 ISSN-e: 2007-7610. https://doi.org/10.31644/ED.V8.N1.2021.A09 
concebida como curativa: la "experiencia espiritual". Sin embargo, para que esta "máquina" siga "produciendo enfermos" es necesario atraer gente, mediante lenguajes y prácticas curativas que los identifique como tales: en este espacio se producen codependientes, alcohólicos, drogadictos, lujuriosos, neuróticos, enfermos emocionales y trastornados.

En consecuencia, este conjunto de prácticas (las juntas, "experiencia espiritual”, entre otras) que dominan los diferentes espacios del grupo, son símbolos que utilizan los integrantes y representan la "manipulación de los sentidos y significados" (Escalona, 2012) o "ideas" (LéviStrauss, 1987). Concluí entonces que, al pasar por este proceso, la mayoría de los integrantes les han o se han autoimpuesto la etiqueta de "enfermos emocionales y físicos", recogiendo de los y las participantes de más tiempo los diversos discursos, interpretados en distintas formas. Todo ello se puede percibir cuando al iniciar el trabajo de escritura en el retiro espiritual, el coordinador les señala a los escribientes que están "enfermos", y que es a través de la "experiencia" como se darán cuenta de cuál es la enfermedad que tienen. En caso de no tenerlo claro, serán los padrinos y madrinas quienes les dirán qué enfermedad padecen. A la par, esta organización “erige barreras simbólicas" (Coser, 1978: 15) entre lo que se considera una persona enferma y una recuperada, para aislarlos de los otros. Es decir, "por la naturaleza misma de su status" (Coser, 1978: 15) de enfermo, algunos/algunas participantes llegan a concebir las acciones "irregulares" de otros como señales de una persona "enferma". Por tanto, la enfermedad y la cura se constituyen como una producción social.

Por último, en este escenario, también pude percibir que no todos los integrantes, a pesar de que están en el grupo, se consideran enfermos emocionales o físicos; otros integrantes mienten cuando se identifican con alguna enfermedad en el grupo. Pero es en este escenario donde algunos miembros intentan, manipulando los lenguajes y las prácticas, que acepten que están enfermos. Asimismo, observé que no todas las personas entran voluntariamente o por engaños, sino que otras entran, a veces, por diversas razones; por ejemplo, presión familiar o de amistad. Por tal motivo, los y las participantes negocian constantemente ${ }^{27}$ (Escalona, 2016) su aceptación; a veces hasta fingiendo.

De este modo, me pareció que para comprender el mundo social de esta organización era más apropiado desmenuzar el grupo y ver las herramientas con las cuales operan. Para intentar dar cuenta de cómo ocurre ese proceso de producción, esto también me dirigió a otros aspectos de la vida social del grupo que jamás imaginé que estuvieran desplegados en el mismo: la producción de varios entendimientos, la enfermedad y la utilización de estrategias para intentar regular a los participantes.

Me pregunto ahora, ¿cómo algunos integrantes llegan a producir cierta habilidad para manejar estos discursos? ¿Cuáles son sus elecciones en cuanto a lo que ven, leen o escuchan?, ¿qué es lo atractivo de esta organización que hace que la gente vaya e incluso permanezca? ¿Por qué las personas se reúnen en este tipo de espacio semi-público para hablar sobre su sexualidad, sus traumas, sus miedos y culpas en un lenguaje diferente? Así que por el carácter de la etnografía de inmersión temporal, no puedo más que mostrar la complejidad de este espacio social y dejar planteadas más preguntas para seguir explorando organizaciones de este

${ }^{27}$ Traducción del autor: "Constant negotiation” (Escalona, 2016: 256).

EntreDiversidades. Revista de Ciencias Sociales y Humanidades, vol. 8, núm. 1 (16), enero-junio 2021. Páginas: 212 - 240 ISSN-e: 2007-7610. https://doi.org/10.31644/ED.V8.N1.2021.A09 
tipo; en donde no entran, por ejemplo, soluciones lineales y simples de dos variables (causas y efectos). Un grupo donde se pueden examinar diversas posibilidades, elementos y variables.

\section{Bibliografía citada}

Alcohólicos Anónimos (AA) Grapevine (1993). Tres Charlas a Sociedades Médicas por Bill W. cofundador de A.A. Alcoholics Anonymous. New York, Estados Unidos de América: Ediciones Alcoholics Anonymous World Services. También disponible en https://dev1. aa.org/assets/es ES/sp-6 threetalkstomed.pdf

Anderson, Brian y Garcia, Angela (2015). "Spirituality' and 'cultural adaptation' in a Latino mutual aid group for substance misuse and mental health". BJPsych Bulletin, 39, pp. 191-195. DOI: https://doi.org/10.1192/pb.bp.114.048322 (Consultado el 16 de junio de 2018).

Appendini, Kirsten y Nuijten, Monique (2002). "El papel de las instituciones en contextos locales: cuestiones metodológicas en investigación de campo". Revista de la CEPAL, 76, pp. 7178. Disponible en: https://www.cepal.org/es/publicaciones/37960-revista-la-cepal-no76 (Consultado el 27 de abril de 2018).

Becker, Howard, (2016). Mozart, el asesinato y los límites del sentido común: Cómo construir teoría a partir de casos. Buenos Aires, Argentina: Edición Siglo Veintiuno.

Bosco, Juan (2017). Mensaje a los grupos de 4to y 5to paso en Perú 2017 [video red social]. Disponible en: https:/www.youtube.com/watch? $\mathrm{v}=$ gaKQHjL9Uis (Consultado el $10 \mathrm{de}$ marzo de 2017).

Bourdieu, Pierre (2006). "Génesis y estructura del campo religioso". Relaciones. Estudios de historia y sociedad, XXVII (108), pp. 29-83. Disponible en: http://www.redalyc.org/ articulo.oa?id=13710803 (Consultado el 10 de marzo de 2019).

Bourdieu, Pierre (2013). El sentido práctico. México: Siglo XXI.

Castro Rosas, Alejandro (2000). ¿Quiénes somos? Central Mexicana de 4 y 5 Paso. [pdf]. Disponible en: $\quad$ http://media.wix.com/ugd/dbe54c df4963f63c5849128d85731ae017afa2.pdf (Consultado el 22 de mayo de 2017).

Córdova Nava, Jesús Rogelio (2018). Juegos de voluntades: el tratamiento de las adicciones en México. Tesis para obtener el grado de Doctorado en Antropología Social. Centro de Estudios Antropológicos, El Colegio de Michoacán. Disponible en: http://colmich. repositorioinstitucional.mx/jspui/handle/1016/425 (Consultado el 20 de junio de 2018).

Coser, Lewis Alfred (1978). Las instituciones voraces. Distrito Federal, México: Fondo de Cultura Económica. También disponible en: http://anchecata.colmich.edu.mx/janium/Tablas/ tabla9377.pdf

Cruz González, Damián (2018). Encontrando mi enfermedad: producción de las relaciones sociales en el grupo nuevo atardecer de cuarto y quinto paso. Tesis para obtener el grado de Maestría en Antropología Social, Centro de Investigaciones y Estudios Superiores en Antropología Social (CIESAS-SURESTE). También disponible en: http://ciesas. repositorioinstitucional.mx/jspui/handle/1015/886

EntreDiversidades. Revista de Ciencias Sociales y Humanidades, vol. 8, núm. 1 (16), enero-junio 2021. Páginas: 212 - 240 ISSN-e: 2007-7610. https://doi.org/10.31644/ED.V8.N1.2021.A09 
Di Pardo, Renée (2009). “La sobriedad como bien”. Desacatos. Revista de Ciencias Sociales, 29, enero-abril, pp. 173-178. Disponible en: https://desacatos.ciesas.edu.mx/index.php/ Desacatos/article/view/440 (Consultado el 22 de mayo de 2018).

Escalona Victoria, José Luis (2008). "Politics and Memories in Rural Chiapas: Languages of Power at the Dawn of the Twenty-first Century". Journal Identities, 15 (5), pp. 550 573. DOI: https://doi.org/10.1080/10702890802333801 (Consultado el 22 de mayo de 2018).

Escalona Victoria, José Luis (2009a). "Para una antropología del poder. Una agenda a partir de trabajos recientes sobre la finca y la comunidad en Chiapas". Anuario de estudios indigenas, vol. XIII, pp. 15-52. También disponible en: https://www.academia.edu/42188420/Para una antropolog\%C3\%ADa del poder Una agenda a partir de trabajos recientes sobre la finca y la comunidad en Chiapas

Escalona Victoria, José Luis (2009b). Politica en el Chiapas rural contemporáneo. Una aproximación etnográfica al poder. Distrito Federal, México: Universidad Nacional Autónoma de México.

Escalona Victoria, José Luis (2012). "Perspectivas etnográficas en Chiapas, México, desde una antropología del poder". Revista Mexicana de Sociología, 74 (4), pp. 533-560. Disponible en: https://www.jstor.org/stable/43495629?seq=1\#page scan tab contents (Consultado en junio de 2017).

Escalona Victoria, José Luis (2014). "Espacios transpuestos: haciendo etnografía entre el campo y la ciudad". EntreDiversidades. Revista de Ciencias Sociales y Humanidades, 2 (primaveraverano), pp. 175-205. DOI: https://doi.org/10.31644/ED.2.2014.a06 (Consultado el 17 de julio de 2018).

Escalona Victoria, José Luis (2016). "Anthropology of power: Beyond state-centric politics”. Anthropological Theory, 16 (2-3), pp. 249-262. DOI: https://doi. org/10.1177/1463499616654370 (Consultado el 22 de mayo de 2018).

Garcia, Angela, Brian Anderson y Keith Humphreys (2015). "Fourth and Fifth Step Groups: A New and Growing Self-Help Organization for Underserved Latinos with Substance Use Disorders, Alcoholism Treatment Quarterly”. Alcoholism Treatment Quarterly, 33 (2), pp. 235-243. DOI: https://doi.org/10.1080/07347324.2015.1018784 (Consultado el 26 de mayo de 2018).

Gluckman, Max (1958). "Análisis de una situación social en Zululandia moderna”. RhodesLivingstone Paper, 28. Manchester, United Kindom. Colección Clásicos y Contemporáneos en Antropología, del Centro de Investigaciones y Estudios Superiores en Antropología Social, Departamento de Antropología de la Universidad Autónoma Metropolitana, Unidad Iztapalapa, Departamento de Ciencias Sociales y Políticas de la Universidad Iberoamericana. Disponible en: https://www.ciesas.edu.mx/publicaciones/clasicos/00 CCA/31 MG 01.html (Consultado el 15 de abril de 2018).

Goffman, Erving (2012). Internados: ensayos sobre la situación social de los enfermos mentales. Buenos Aires, Argentina: Amorrortu Editores.

EntreDiversidades. Revista de Ciencias Sociales y Humanidades, vol. 8, núm. 1 (16), enero-junio 2021. Páginas: 212 - 240 ISSN-e: 2007-7610. https://doi.org/10.31644/ED.V8.N1.2021.A09 
González Montiel, Jessica (2015). ¡Compañeros, soy libre! Experiencias y silencios masculinos en grupos de 4 to y 5 to paso. Tesis para obtener el grado de Maestría en Estudios Políticos y Sociales, Facultad de Ciencias Políticas y Sociales, Universidad Nacional Autónoma de México (UNAM). DOI: https://ru.dgb.unam.mx/handle/DGB UNAM/TES01000736537 (Consultado el 6 de marzo de 2017).

Grupos de Cuarto y Quinto Paso de Amor y Servicio (2012). Grupos de Cuarto y Quinto Paso de Amor y Servicio. [publicacón red social] 15 de enero de 2015. Disponible en: https:// www.facebook.com/gruposdecuartoyquintopaso/posts/840013402727693 (Consultado el 10 de marzo de 2017).

Gutiérrez Portillo, Ángel Alejandro (2014). "La religiosidad de Alcohólicos Anónimos”. Revista Cientifica de Investigaciones Regionales, 36 (2), abril-septiembre, pp. 73-96. Disponible en: https://www.redalyc.org/pdf/4558/455845084003.pdf (Consultado el 3 de enero de 2017).

Lévi-Strauss, Claude (1987). Antropología Estructural. Buenos Aires, Argentina: Ediciones Paidós.

Martín Ferrari, Leonardo, et al. (2000). "Las aportaciones de los grupos de autoayuda a la salud mental”. Revista Clínica y Salud, 11 (2), pp. 231-256. Disponible en: https://www.redalyc. org/pdf/1806/180618250004.pdf (Consultado el 30 de mayo de 2018).

Menéndez, Eduardo Luis (2009). "De rituales y subjetividades. Reflexiones sobre algunas características de los grupos de Alcohólicos Anónimos". Desacatos. Revista de Ciencias Sociales, [en línea] 29, enero-abril, pp. 107-120. Disponible en: https://desacatos.ciesas. edu.mx/index.php/Desacatos/article/view/435 (Consultado el 13 de enero de 2017).

Menéndez, Eduardo Luis (1991). "Alcoholismo y proceso de alcoholización; la construcción de una propuesta antropológica”. Antropología del alcoholismo en México: los límites culturales de la economía politica (1930-1979). México: Centro de Investigaciones y Estudios Superiores en Antropología Social, pp. 13-32.

Módena, María Eugenia (2009). "Diferencias, desigualdades y conflicto en un grupo de Alcohólicos Anónimos”. Desacatos. Revista de Ciencias Sociales, [en línea] 29, enero-abril, pp. 31-46. También disponible en: https://desacatos.ciesas.edu.mx/index.php/Desacatos/ article/view/431 (Consultado el 15 de enero de 2017).

Nuijten, Monique (2005). "Power in practice: a force field approach to natural resource management". The Journal of Transdisciplinary Environmental Studies, 4 (2), pp. 1-14. Disponible en: https://journal-tes.dk/NewFiles/page\%20one\%208.html (Consultado el 22 de mayo de 2018).

Odgers Ortiz, Olga y Olivas Hernández, Olga Lidia (2018). "Introducción”. ¿Dejar las drogas con ayuda de Dios? Experiencias de internamiento en centros de rehabilitación fronterizos. México: El Colegio de la Frontera Norte, pp. 13-28.

Pinto Durán, Astrid Maribel y de la Cruz López Moya, Martín (2011). "Extraterrestres en el imaginario New Age: redes de espiritualidad y utopía desde San Cristóbal de Las Casas, Chiapas". Revista LiminaR. Estudios sociales y humanísticos, IX (2), pp. 63-82. Disponible en: http://liminar.cesmeca.mx/index.php/r1/article/view/48/40 (Consultado el 18 de febrero de 2017).

EntreDiversidades. Revista de Ciencias Sociales y Humanidades, vol. 8, núm. 1 (16), enero-junio 2021. Páginas: 212 - 240 ISSN-e: 2007-7610. https://doi.org/10.31644/ED.V8.N1.2021.A09 
Rosovsky, Haydée (2009). "Alcohólicos Anónimos en México: fragmentación y fortalezas". Desacatos. Revista de Ciencias Sociales, [en línea] 29, enero-abril, pp. 13-30. Disponible en: https://desacatos.ciesas.edu.mx/index.php/Desacatos/article/view/430 (Consultado el 20 de enero de 2017).

Saussure, Ferdinand de (1998). Curso de lingüistica general. 12a edición. Distrito Federal, México: Editorial Fontamara.

Vega Baca, Juan José (2009). Avatares y desavenencias en la modernidad: grupos de cuarto y quinto paso. Tesis para obtener el grado de Licenciatura en Psicología, División de Ciencias Sociales y Humanidades, Universidad Autónoma Metropolitana. Unidad Xochimilco, Distrito Federal, México.

White, William L. (2015). The History of 4th and 5th Step groups: An interview with Dr. Angela Garcia. [en línea] Selected Papers of William L. White. Disponible en: http://www. williamwhitepapers.com/pr/History\%20of\%204th\%20and\%205th\%20Step $\% 20$ Groups\%20Dr.\%20Angela\%20Garcia.pdf (Consultado el 26 de mayo de 2018).

Wolf, Erick Robert (2014). Europa y la gente sin historia. Segunda edición. México: Fondo de Cultura Económica. 


\section{Anexo \\ CARACTERÍsticas generales de los PARTiCipantes Del grupo Nuevo Atardecer}

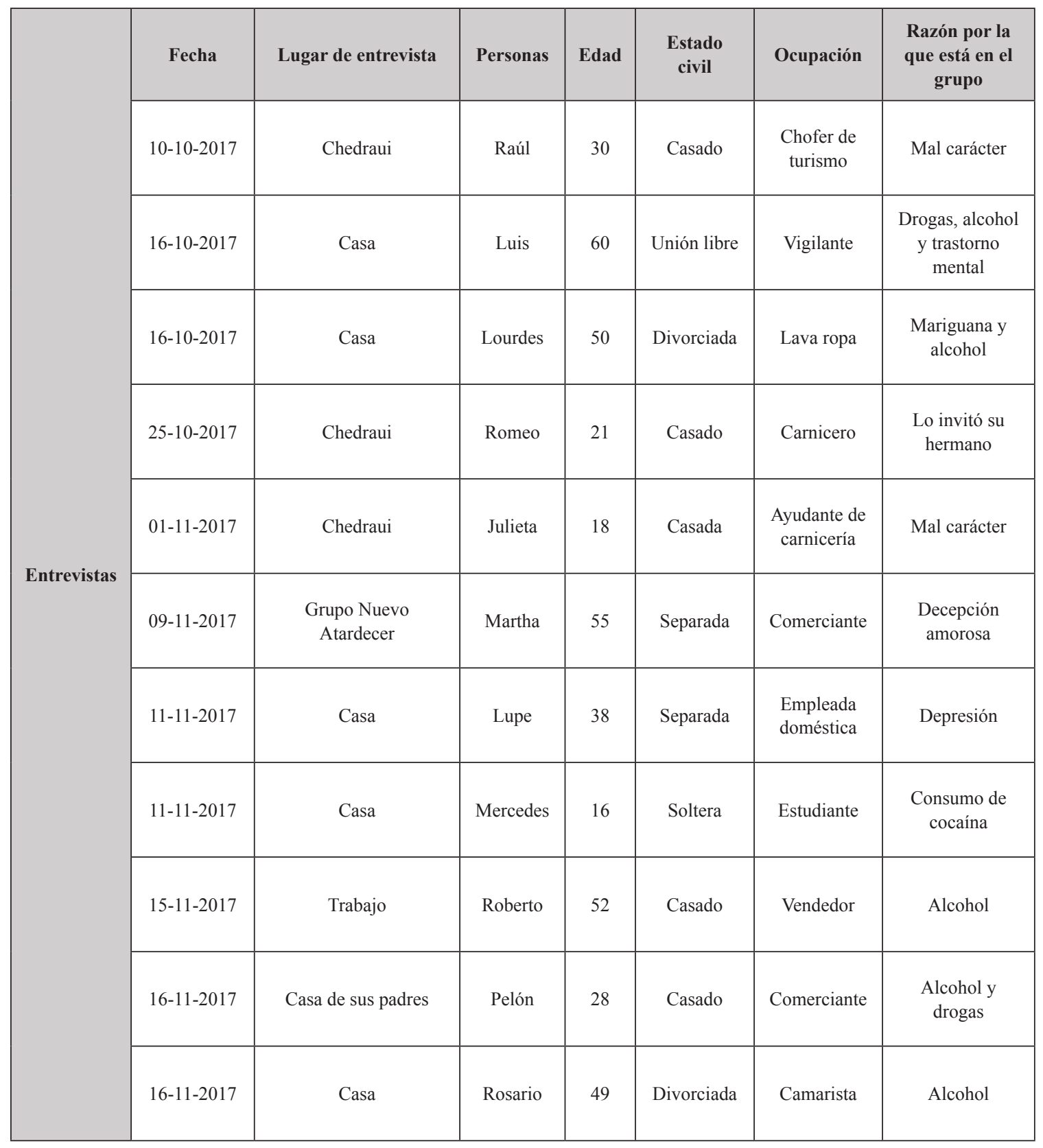

EntreDiversidades. Revista de Ciencias Sociales y Humanidades, vol. 8, núm. 1 (16), enero-junio 2021. Páginas: 212 - 240 ISSN-e: 2007-7610. https://doi.org/10.31644/ED.V8.N1.2021.A09 